\title{
Progress in the Assessment of Complex Components
}

ERWIN SOMMER

Fraunhofer-Institut für Werkstoffmechanik, Wöhlerstr. 11, 7800 Freiburg, FRG

1.

INTRODUCTION

One of the important aims of fracture mechanics is the development of methods for assessing the integrity of components and structures. Unfortunately the complexity of the problem allows only partial solutions taking into account the variety of structures due to their differences in material properties, loading as environmental conditions and geometrical design. From experience is known that failure is most likely initiated at defects, inclusions, flaws, cracks. Therefore, most of the procedures concentrate on the investigation of structures containing real or postulated defects or cracks.

Since investigations of full-size structures are time-consuming and expensive the basic idea is to simulate the most severe features of the material conditions and the loading situations feature under labotosults obtained in under to uantify the margin of safety of the components, their availability or their remaining lifetime by extrapolation.

The main concern is how to abstract a "typical" material condition or loading ituation of a component and to model it in a tion or loading can be of importance for the final failure. In general the cpectrum of parameters is so wide that the transferability of spectrum or param to results from be obtained whose range of validity strictly has to be obbe obtained whose range of solution is, the less represenserved. The more general a solution situation in a structure.

one of the most suitable methods developed for assessing components containing known or postulated defects is the R6 components containing known or postulatedsment diagram. This procedure for constructing a failure assion of a structure by 
reference to the two principal criteria: fracture or plastic collapse. Depending on the purpose of the analysis and the availablility of test data three different categories of

assessment procedures with increasing resolution can be se-

lected to evaluate (Milne et al., 1986)

- the limiting load to avoid failure of a structure

the limiting crack size of the structur subjected to a

specific loading condition

- the reserve factors on the assessed conditons

the sensitivity of these reserve factors to the assessed The R6 protions and details of the analysis.

The R6 procedure embraces a worldwide experience in fracture mechanics and covers a wide range of application.

Nevertheless there are still remaining assessment problems of practical interest which are concerned with the investigation of situations or parameter variations excluded in the R6 procedure or covered in a generalizing manner.

According to the R6 procedure the integrity of a structure for example is evaluated with reference to an existing or postulated flaw, a single load application below the creep range and a material-specific resistance against failure. When changes of the size or the shape of the defect due to critical flaw growth by mechanisms such as ductile or subfatigue and environmentally assisted crack dotile tearing, expected they independently have to be accounted are to be more in many cases not only the onset of failure, for Further complete failure process has to be assessed. break" considerations may stand as a typical example.

For further refinement of assessment procedures the following discussion will concentrate on some investigations of this kind as

The growth characteristics of cracks extending in components of ductile behavior. These characteristics are

a precise description of the complete failure process or prediction of the remaining lifetime as well as for the assessment whether initial defects will change in size or

the discussion of three-dimensinal effects such as parameter variations which influence

the local loading parameters along the contour of cracks as well as

- the local fracture resistance.

Complete other areas as the progress in the assessment of fracdiscussion.

\section{GROWTH CHARACTERISTICS OF CRACKS}

In order to provide information on a stable or subcritical extension of a defect to be assessed or even on the probable

behavior of cracks has to be investigated. Due to the number of variables involved analytical predictions are in general extremely difficult.

Since one of the most dangerous defect configuration is given syce by a crack under the surface of facturing, hare most likely to exist many investigations have been devoted to surface crack problems.

According to the principles of fracture mechanics it is exAccording to front fracture pected that at any locally released energy should initiate ature exceds the resistance are the local loading sitused varying usualiy in a simp loading parameter with on the compar is unknown for the minimula the real dect the lowest resistance guarantees a most sever may be too conservative.

For a more precise evaluation the distribution of the loading parameters and the fracture resistance along the contour of the crack to be assessed have to be known. Depending upon the mechanisms of failure to be expected the first part of the problem without too great difficulties can be solver $\mathrm{K}(\mathrm{s})$, the ing the variation of the elastic regime strain energy release rate $G(s)$ governing the or $J(s)$ in the elastic-plastic reg configurations under solutions especially for surface available in remote tension or bending in plates or pipes 1972, McGowan, the literature, (e.g. Newman, 19 Noack, 1987). The second part 1980, Schmite, 196, Brockination of the local fracture resiof the problem, the determination of the local fracture resistance at the contour is even more challenging. The local resistance only experimentally can be obtain for the sake of methods for the determination are lacking for thed. As such a simplicity a constant resistance often is assumed. As such simplified example the loading situation in aig. with a constant resistance is conside refers to the initiation and beginning growth of the crack in a stable or unstable and beginning growth of the crack in a stable subcritical manner. The same consideration will applytally assisted. That growth of cracks by fatigue or environmentally assisted. That the assumption of a constant resistance along the contour be comes doubtful the more plastic deformation at the che occurs simply can be demonstrated by the changes in the shape of cracks propagated by fatigue with increasing load steps (Hodulak et al., 1978, 1977a) (Fig. 2). From experimental in vestigations it is known that in some cases the maximum of crack growth does not correspond to the maximum of the loading parameter. The "canoeing" effect observed for cracks propagat ing in a ductile manner (Sommer et al., 1977, Brocks et al. loading parameter only. Agreement can be obtained when in 

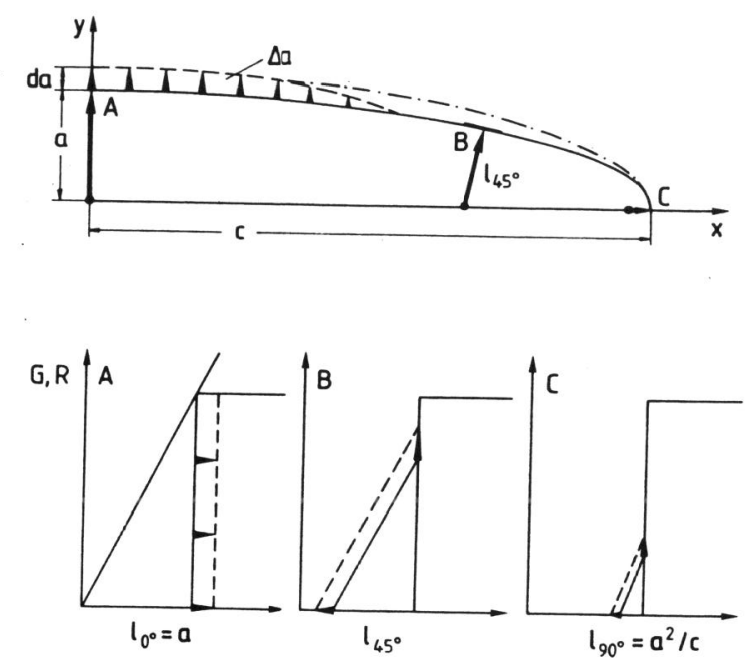

Fig. 1. Local Fracture Initiation of a surface crack $(\mathrm{a} / \mathrm{c}=\mathrm{a} / \mathrm{t}=0.2)$ in a Plate under erack Brittle Material Behavior; Constant Fracture Resistance Along the Contour.
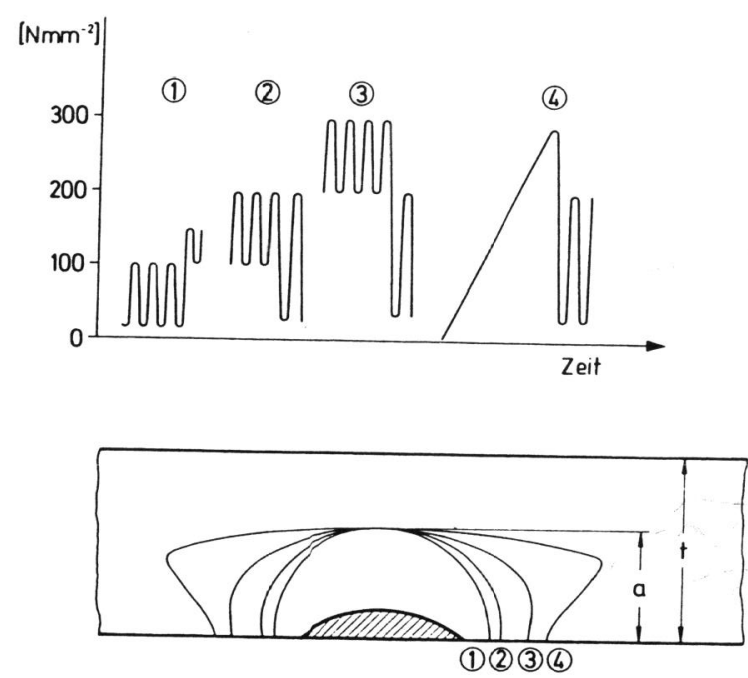

Fig. 2. Resulting Crack Shapes for $a / t=0.6$ Under Various Loading Conditions.

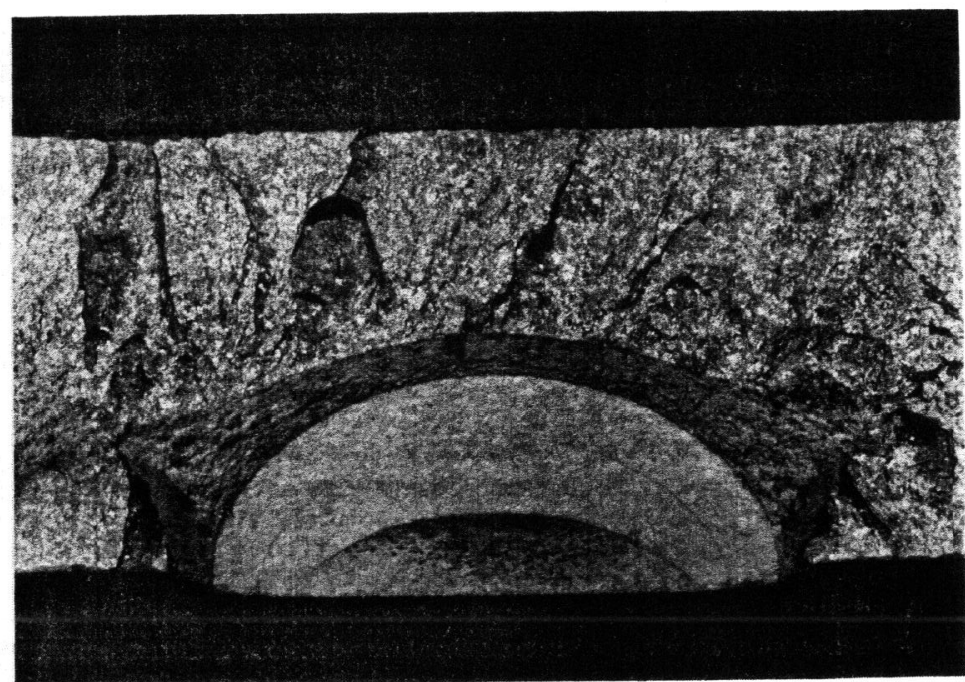

Fig. 3. Fracture Surface in a Prefatigued plate of 22 NiMoCr 37 under Uniform Tension Showing Canoeing Effect.

For the explanation of three-dimensional effects a careful in terpretation of results obtained under simplifying "two-dimensional" or plane conditions is helpful.

\subsection{Observations in Plane Specimens}

From fracture test results carried out in plane specimens of the same material it is known that the onset and growth of fracture is strongly affected by the temperature, the strain rate and the prevailing stress state. In such plane specimen configurations which contain cracks with a more or less straight front - in contrast to the surface crack problem usually the loading and the resistance parameters are tacitly defined as mean values averaged in the thickness direction ( $\mathrm{s}$ section "Correlation of Fracture Resistance and Multiaxiality"). This allows to suppress a discussion on their possible variation along the contour. Correspondingly information on the stress state is only available in an averaged form. The importance of this fact will be stressed in the following discussion.

since the state of plane strain is considered as the most dangerous one - care is taken by restricting the design of specimens for the determination of fracture toughness values as $\mathrm{K}_{\mathrm{Ic}}$ or $\mathrm{J}_{\mathrm{Ic}}$ in such a way that in the near field of the crack tip this stress state dominates (ASTM Standards, 1969, ASTM E 813-82). 
The slope of fracture resistance curves as $J_{R}$ versus $\Delta a$ is even more affected by the global and local constraint of the speciprovide the most severe specimens of sufficient thickness resist nounced in curves or the lowest slope. This effect is prowith brittlotior as metals. Material sistarle slow variation in the che. These changes in slope, however, are mainly dominated in the path dependent fracture mechanisms

\subsubsection{Fracture Initiation and Resistance}

For a refined interpretation of these effects based on a distinct separation of the parameter of main influence raprresults with a limited scatter have to be

The onset of brittle fracture of specimens under monotonically increasing, but quasistatic loading can be uhar motonically well known relatively simple manner using instability based on LEFM-methods by critical values of the parameterer stress intensity factor $\mathrm{K}$ or strain energy release raters the

2.1.1.1. Fracture Initiation and Resistance in Ductile Materials

For the characterization of the initiation toughness of ductile materials the following evaluation procedures are often used (Blauel et al. 1984)

J Ic $^{\text {ASTM }}$ : technical initiation toughness - evaluated from a

linear fit to the $J_{R}$-curve according to ASTM E 813-81

$\mathrm{J}_{\text {Ic }}{ }^{\text {Loss }}$ :

technical initiation toughness - evaluated from a power law fit according to (Loss et al. (1979)

physical initiation thoughness - estimated as the first point of deviation of the $\mathrm{J}_{\mathrm{R}}$-curve from the formal blunting line.

As an example the toughness of the reactor pressure vessel ation 20 MnMoNi 55 deternined according to the several evaluwithin the pronounced $J$-values seem to be independent of the results these $i$ ind geometry parameters - at least in the range of variation of CT 25 to CT 100 with and without sidegrooves - and of temp CT 25 to CT 100 with and
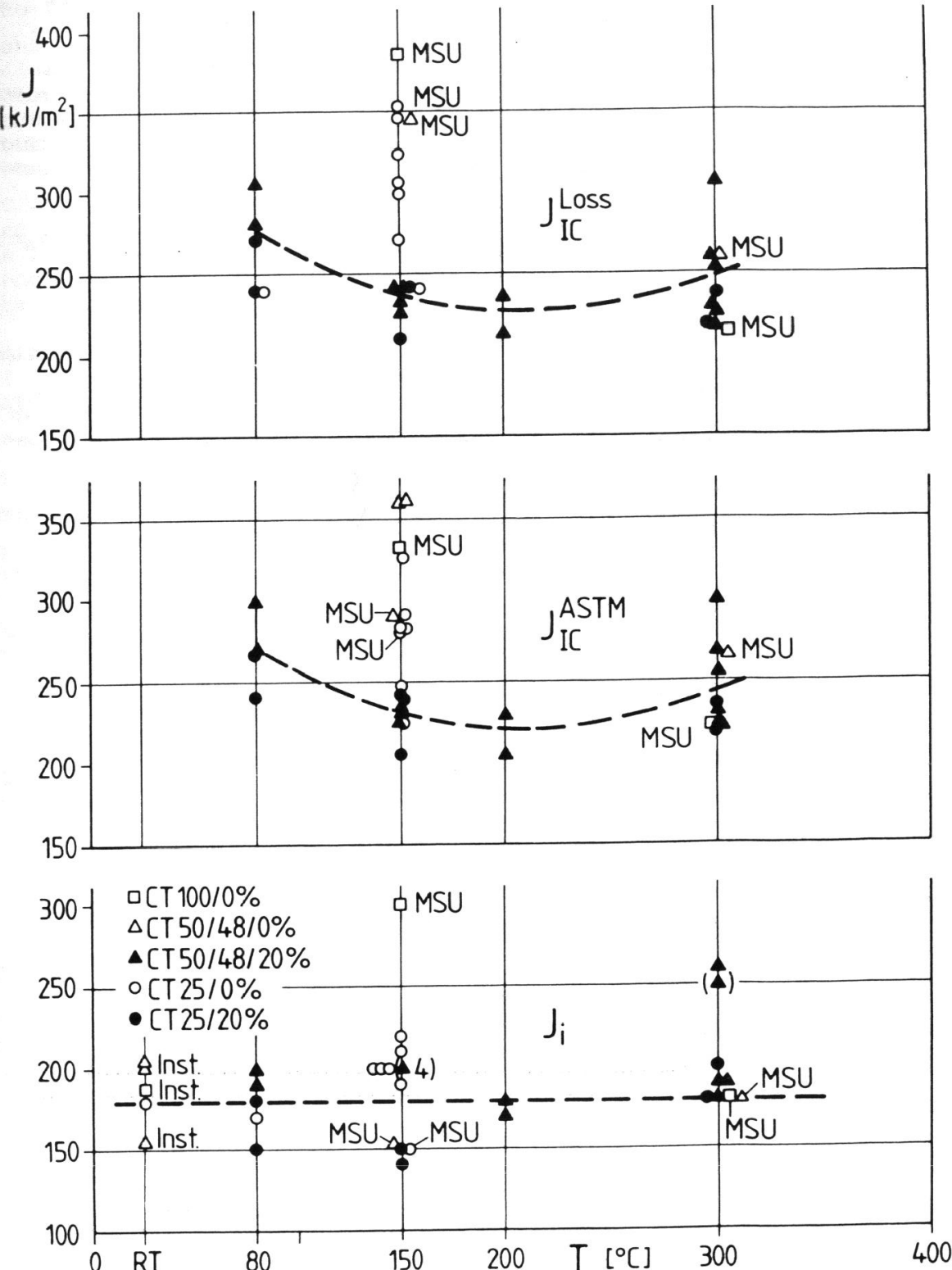

Fig. 4. Initiation Toughness as a Function of Temperature. Pressure Vessel steel 20 MnMoNi 55. (Blauel et al. 1984.) 
variation $\mathrm{RT}$ to $300^{\circ} \mathrm{C}-$. The resulting mean value is $\mathrm{J}_{i}{ }^{\text {mean }}=$ $180 \mathrm{~N} / \mathrm{mm}$.

The "technical" toughness values do not describe the real initiation of fracture. They are determined after a finite amount the physic in ture trends initiation toughness values. In addition temperature trends can be observed at about $200^{\circ} \mathrm{C}$.

These experimental results are confirmed for different steels by the findings of other authors (Roos et al., 1987).

Since $J_{i}$-values of this kind are determined from the first change in the slope of $\mathrm{J}_{R}$-curves it has to be recalled that the J-evaluation is a procedure averaging over the thickness and in addition is related to the net section of the ligament when specimens with and without sidegrooves are considered. The experimental error of about 10 to $20 \%$ in general obscures a more precise interpretation of these test results. Trends which allow an even more refined assessment can be observed and stance and Multiaxiality".

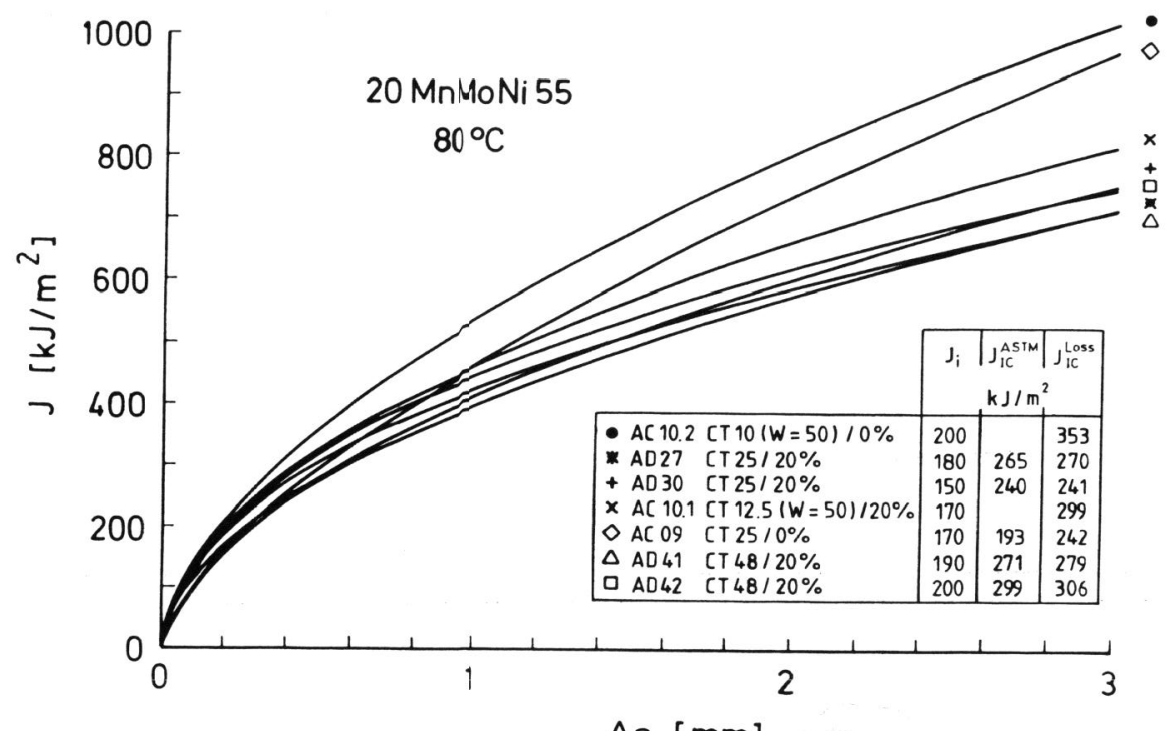

$\Delta \mathrm{a}[\mathrm{mm}]$

Fig. 5. $\mathrm{J}_{\mathrm{R}}$-Curves and critical $\mathrm{J}_{i}$-Values obtained from Different CT-Specimens at $80^{\circ} \mathrm{C}$ with the Pressure Vestoding Technique for the Reactor 20 MnMoNi 55. (Blauel
The influence of the specimen geometry on $\mathrm{J}_{R}$-curves due to constraint effects is demonstrated in Fig. 5 by results obtained for the reactor vessel steel 20 MnMoNi 55 at $80^{\circ} \mathrm{C}$ (Blauel et al., 1984) which may stand for similar results of other authors (Roos et al., 1987). Seven CT-specimens ranging from 10 to 48 with and without sidegrooving have been investigated. The resulting slope of the $\mathrm{J}_{\mathrm{R}}$-curves is steepest for the CT ( $0 \%$ s.g.) 10 and 25 and lowest for the CT $(20 \%$ s.g. $) 48$ and 25 ; the slope of the CT $(20 \%$ s.g. $) 12.5$ specimen is almost and 25 ; the slope of the CT (20\% S.g.) 12.5 specimen is almost conclusion that the $20 \%$ sidegrooving has a stronger effect on the slope than doubling the specimen thickness.

In order to establish quantitative results on the reliability tal and material scatter of $\mathrm{J}_{\mathrm{R}}$-curves the European Group on Fracture, Task Group I, carried out round robin investigations supported by 13 laboratories (Blauel and Voss, 1986). $\mathrm{J}_{\mathrm{R}}$-curves are analyzed by various techniques according to the position of the specimens in one of three layers across the thickness of a plate of the steel A 542. As demonstrated in Fig. 6 the scatter within each subset is less than the lotal scatterband. The specimens taken from the center layer of the plate have a lowe resistance compared to the specimens taken from the near surface. In conclusion

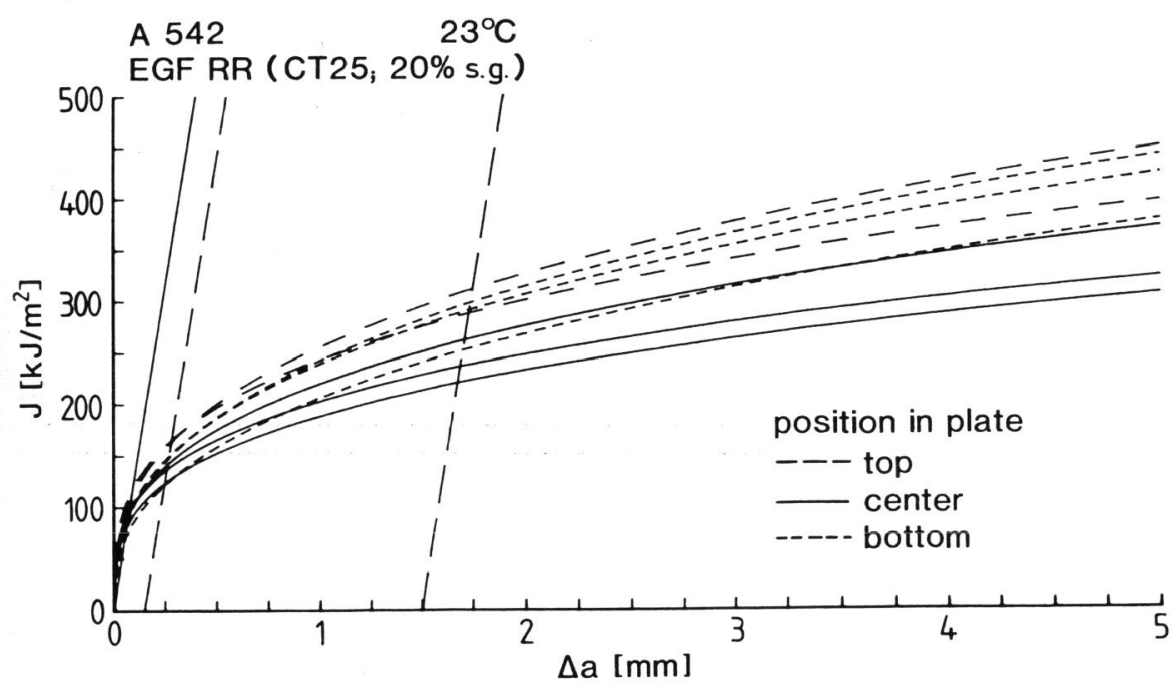

Fig. 6. $J_{R}$-Curves obtained by Regression $J=C \Delta a^{n}$ for Sidegrooved CT 25 specimens Investigated by 13 Different Laboratories (EGF Round Robin) at $23^{\circ} \mathrm{C}$; Steel A 542. (Blauel and Voss, 1986.) 
high standard of the single specimen method allows to resolve problem of the influe fluence of constraint on the slope of $\mathrm{J}$ curves.

\subsubsection{Multiaxiality Parameter}

The constraint is considered to be the restraint of plastic de ouantitatively to the conplete stress state in the specimen. ductilatively the term constraint is difficult to define. For ductile fracture the multiaxiality parameter

$\sigma_{\mathrm{m}} / \sigma_{\mathrm{v}}=\mathrm{h}(\mathrm{r}, \varphi, \mathrm{s})$

successfully has been applied

to characterize the local constraint at the crack tip

(Clausmeyer, 1969, Roos et al., 1986, BAM-Forschungsbericht, 1987)

$\sigma_{\mathrm{m}}=\left(\sigma_{1}+\sigma_{2}+\sigma_{3}\right) / 3=$ mean stress and

$\sigma_{v}=2^{-1 / 2}\left[\left(\sigma_{1}-\sigma_{2}\right)^{2}+\left(\sigma_{3}-\sigma_{1}\right)^{2}+\left(\sigma_{2}-\sigma_{3}\right)^{2}\right]^{1 / 2}=$

$=$ equivalent stress

evaluated in dependence on the crack tip coordinates $r, \varphi, s$. It is expected that the constraint rip coordinates $r, \varphi, \mathbf{s}$. $\sigma_{\mathrm{m}} / \sigma_{\mathrm{v}}=\mathrm{h}(\mathrm{r}, \varphi=0, \mathrm{~s})$ on the ligament is most important for mode I fracture. Therefore only the function $\sigma_{\mathrm{m}} / \sigma_{\mathrm{v}}=\mathrm{h}(\mathrm{r}, \mathrm{s})$ is in in dependence of the parameter $s$ at a certain distance $r$ from
the crack tip.

The importance of this parameter will be demonstrated by numerical calculations which simulate experimentally investigated MoCr 37 at $\mathrm{RT}$. The

Fig. 7; two of the curves with a higher resolution in Fig. 8. The stress-strain- curve of the material is assumed to be a multilinear curve, the $1 / \mathrm{r}$-singularity of the crack tip strain th collapsed isoparametric elements. The radius of curvature of the sidegrooves is modelled by $\rho=0.25 \mathrm{~mm}$ improving the results reported in (Kordisch and sommer, 1986).

The variation of $\mathrm{J}$ along the crack contour for both specimen configurations is computed by the virtual crack extension method using IWM-Crack (INM-CRACK, 1988) and plotted in Figs a and b for several load steps. For the CT-specimen without

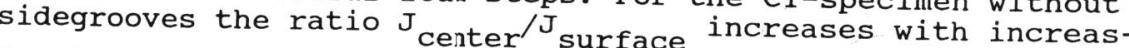
ing load. For the CT-specimen with sidegrooves $J$ is relatively constant and decreases only slightly towards the free surface.

Figs. $10 \mathrm{a}$ and $\mathrm{b}$ show the corresponding variation of the factor of multiaxiality $\sigma_{\mathrm{m}} / \sigma_{\mathrm{v}}$ along the crack contour evaluated on the ligament at a distance $0.24 \mathrm{~mm}$ from the crack tip. With increasing displacement $\sigma_{\mathrm{m}} / \sigma_{\mathrm{v}}$ approaches a limiting value in the center of both specimens of $\left(\sigma_{\mathrm{m}} / \sigma_{\mathrm{v}}\right)_{\mathrm{l}}=2.8$. When $\sigma_{\mathrm{m}} / \sigma_{\mathrm{v}}=$ $h(r, s)$ is calculated by $F E$-methods the accuracy of the results obtained depends on the technique used for modelling the crack tip field, the type and mesh size of the elements (Brocks and Noack, 1987, Kordisch et al., 1987). Most commonly used is the collapsed element technique which allows modelling of e.g. $1 / r$-singularities in the strains and non-zero crack tip dis placements. If no geometric non-linearities are considered (material non-linear only MNLO-option In ADINA, (Bathe, 1980) the element stiffness matrices built are based on the original undisplaced position of the nodal points and thus this singular behavior is maintained throughout the analysis for all load steps. In such an analysis the stress components evaluated at the integration points increase towards the crack tip according to the singular behavior of the strains and to the non-linear material description. If in addition also geometric non-linearities are taken into account (e.g. the updated Lagrangian UL-option in ADINA) and a fine mesh size is used the computed function $\sigma_{\mathrm{m}} / \sigma_{\mathrm{v}}=\mathrm{h}(\mathrm{r})$ shows a maximum at a definite distance from the crack tip. For the same material properties and the same J-level this maximum is mainly affected by the effects related to the specimen geometry (BAM-Forschungsbericht, 1987, culation under the assumption of non-linear material behavior

$J_{R}$ - curves

$22 \mathrm{NiMoCr} 3725^{\circ} \mathrm{C}$

$\mathrm{CT} 20, \mathrm{a} / \mathrm{W}=0.58$

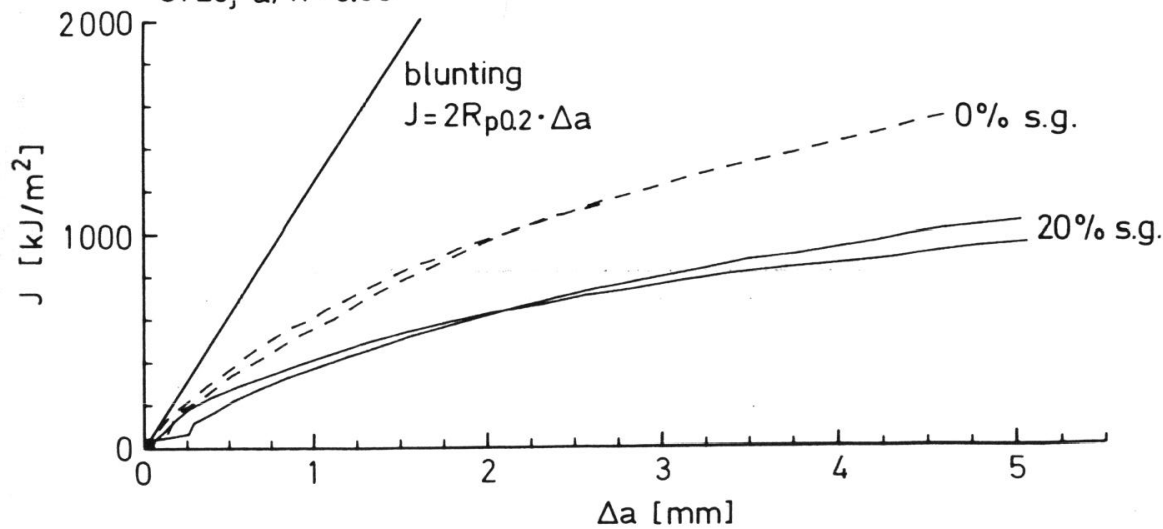

Fig. 7. $\mathrm{J}_{\mathrm{R}}$-Curves at CT 20 Specimens $0 \%$ and $20 \%$ Sidegrooved; Reactor Pressure vessel steel. (Kordisch et al., 1987). 

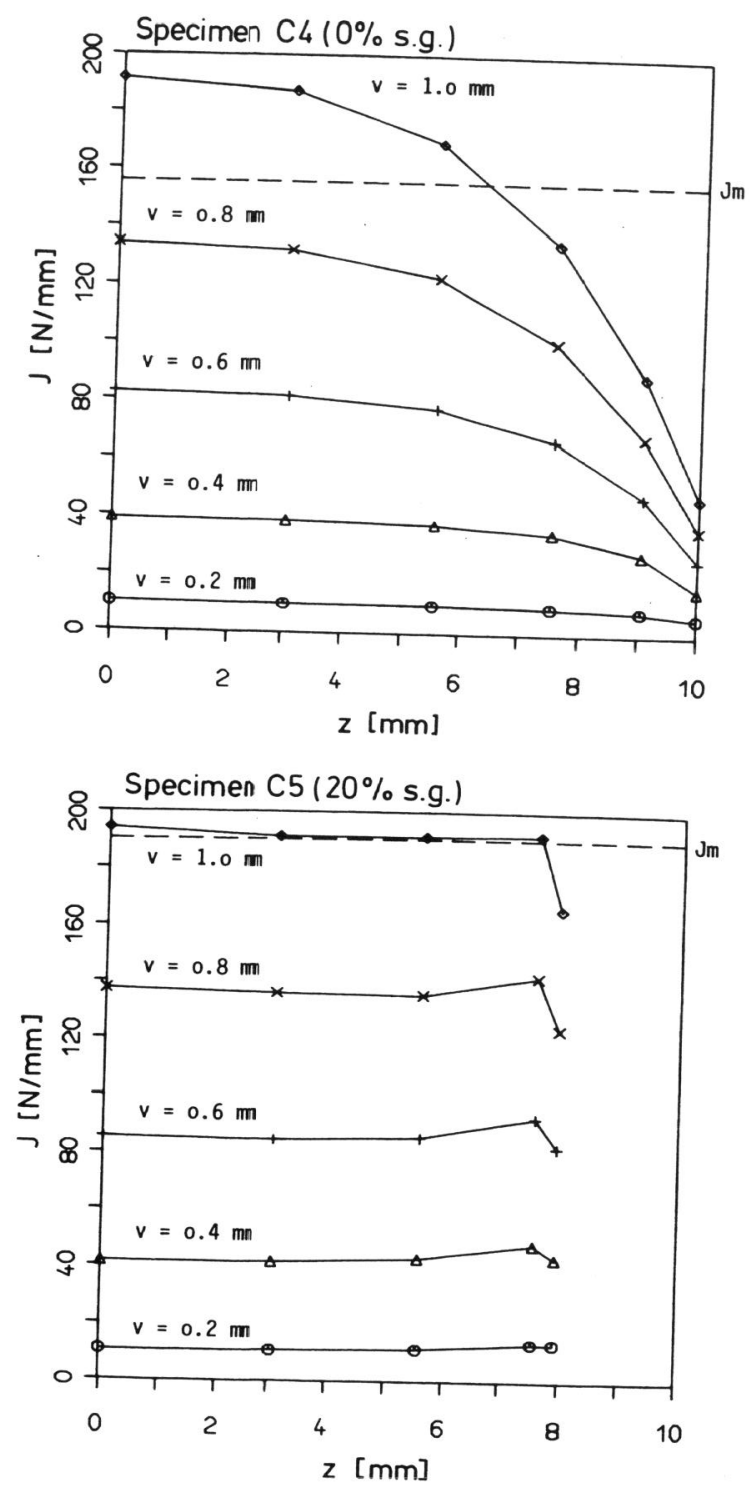

Figs. 9 a and b. J Along the Crack Front of Compact-Specimens with $(20 \%)$ and without
Sidegrooving.

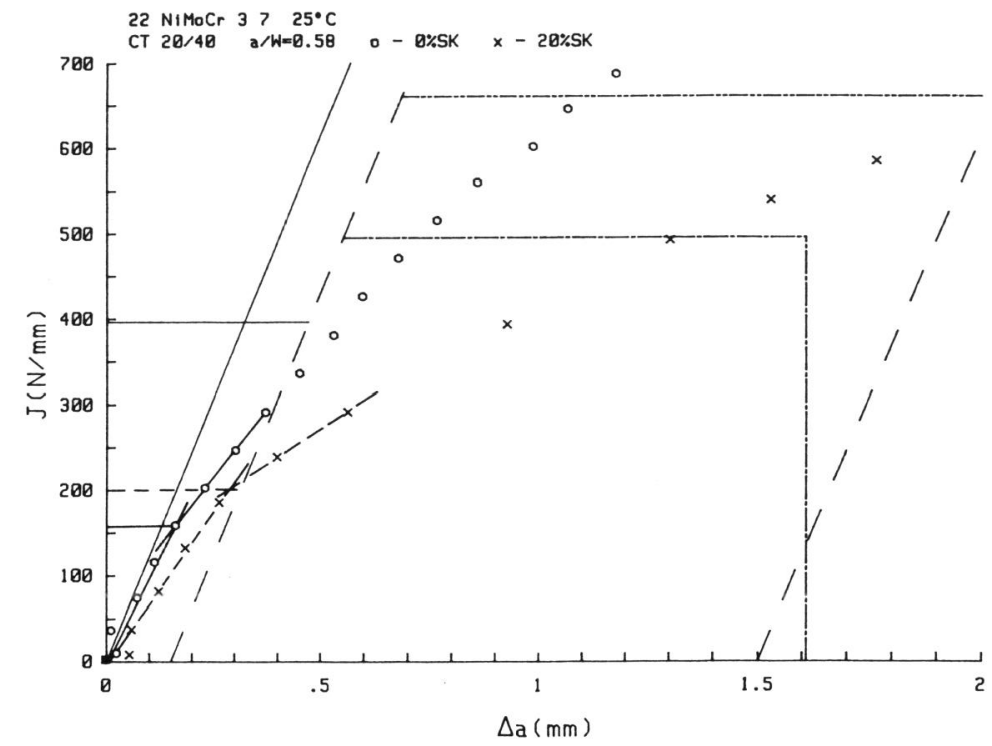

Fig. 8. Details of Fig. 7; Two Curves Selected from Four in order to Demonstrate the Difference in the Onset of Stable Crack Growth for Specimens $0 \%$ and $20 \%$ s.g. only (MNLO) as a kind of integrating approach applied in an extrapolation to the crack tip (r 0$)$ leads to limiting an extrapolation to the crack tip ( values which correspond roughly to the maximation reported in by the other modelling technique the calculation reported in (Kordisch et al., 1987).

2.1.3. Correlation of Fracture Resistance and Multiaxiality

Both specimen configurations show for the same step of external displacement in the center the same value of the loading parameter $J$ as well as the limiting value of the paramete $\left(\sigma_{m} / \sigma_{v}\right)$

When fracture is assumed to be initiated as a local event at a -value fracture in both cases should start initiation at the same central $\mathrm{J}$-value inspite of the differences in the
$\mathrm{J}$-distribution caused by the specimen geometry. That this hypothesis is in agreement with experimental findings can be indirectly proved The two single $\mathrm{J}_{\mathrm{R}}$-curves plotted in Fig. 8 which are obtained from a CT-specimen with $(20 \%)$ and without $(0 \%)$ 

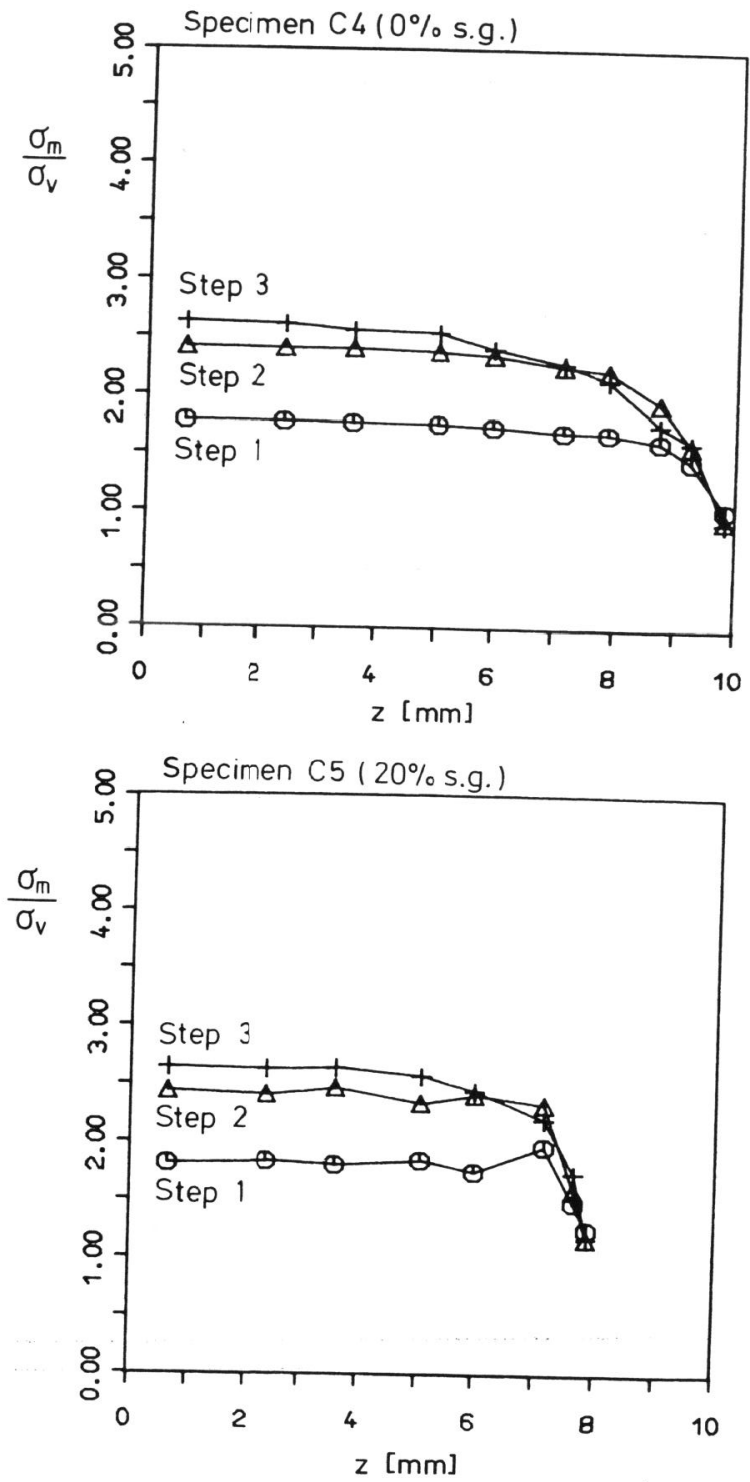

Figs. $10 \mathrm{a}$ and $\mathrm{b}$. Parameter of Multiaxiality $\sigma_{\mathrm{m}} / \sigma_{\mathrm{v}}$ Along the crack Front of the Same specimens.

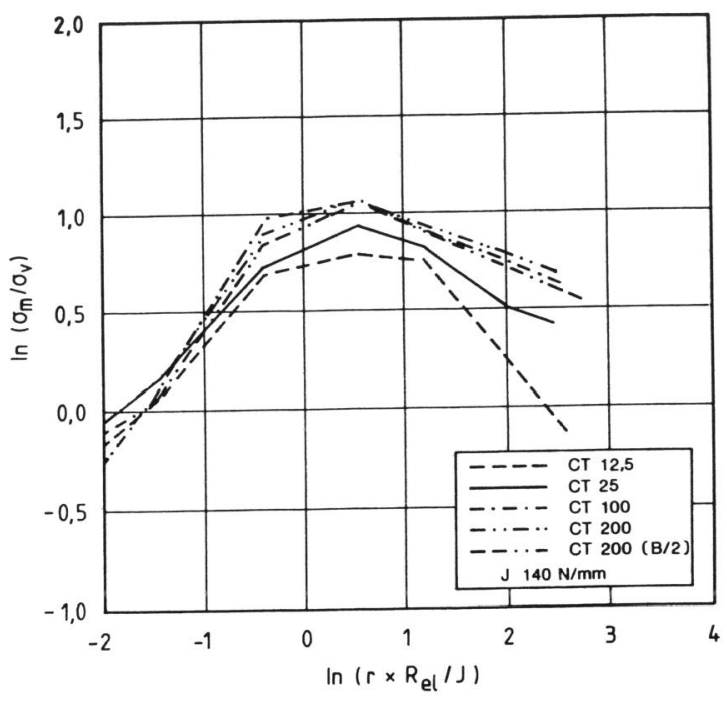

Fig. 11. Parameter of Multiaxiality $\sigma_{\mathrm{m}} / \sigma_{\mathrm{v}}$ in CompactSpecimens Versus the Normalized Ligament coordinate in the Midsection of the Specimen. (Brocks et al. 1987.)

widegrooving allow to determine fracture initiation values. These are the average values: $J_{\mathrm{mi}}(20 \% \mathrm{s.g.})=200 \pm 20 \mathrm{~N} / \mathrm{mm}$ and $\mathrm{J}_{\mathrm{mi}}(0 \% \mathrm{s.g.})=160 \pm 20 \mathrm{~N} / \mathrm{mm}$. The numerically calculated plots of the J-distribution along the contour of the specimens with and without sidegrooves in Fig. $9 a$ and $b$ show that for the same local value $J_{i}=190 \mathrm{~N} / \mathrm{mm}$ different average values $\mathrm{J}_{\mathrm{mi}}$ of the same order as experimentally obtained results.

For the same step of external displacement the same local values in the center of the two specimen configurations result but different mean values $\mathrm{J}_{\mathrm{m}}$ and $\left(\sigma_{\mathrm{m}} / \sigma_{\mathrm{v}}\right) \mathrm{m}^{\text {. They are defined }}$ as the weighted integral over the thickness $\mathrm{B}$ :

$J_{\mathrm{m}}=\mathrm{B}^{-1} \int \mathrm{J}(\mathrm{z}) \mathrm{dz} \quad$ and $\left(\sigma_{\mathrm{m}} / \sigma_{\mathrm{v}}\right)_{\mathrm{m}}=\mathrm{B}^{-1} \int\left(\sigma_{\mathrm{m}} / \sigma_{\mathrm{v}}\right)(z) \mathrm{dz}$

When fracture resistance curves - J exp versus stable crack growth $\Delta a$ - experimentally are determined $J$ exp has to be considered as the average value $\mathrm{J}_{\mathrm{m}}$. The parameter $\left(\sigma_{\mathrm{m}} / \sigma_{\mathrm{v}}\right)_{\mathrm{m}}$ obtained at a certain distance from the crack tip for corresobtained at a certain distance from the crack tip the observed ponding specimen geometries can help to explain the observ 


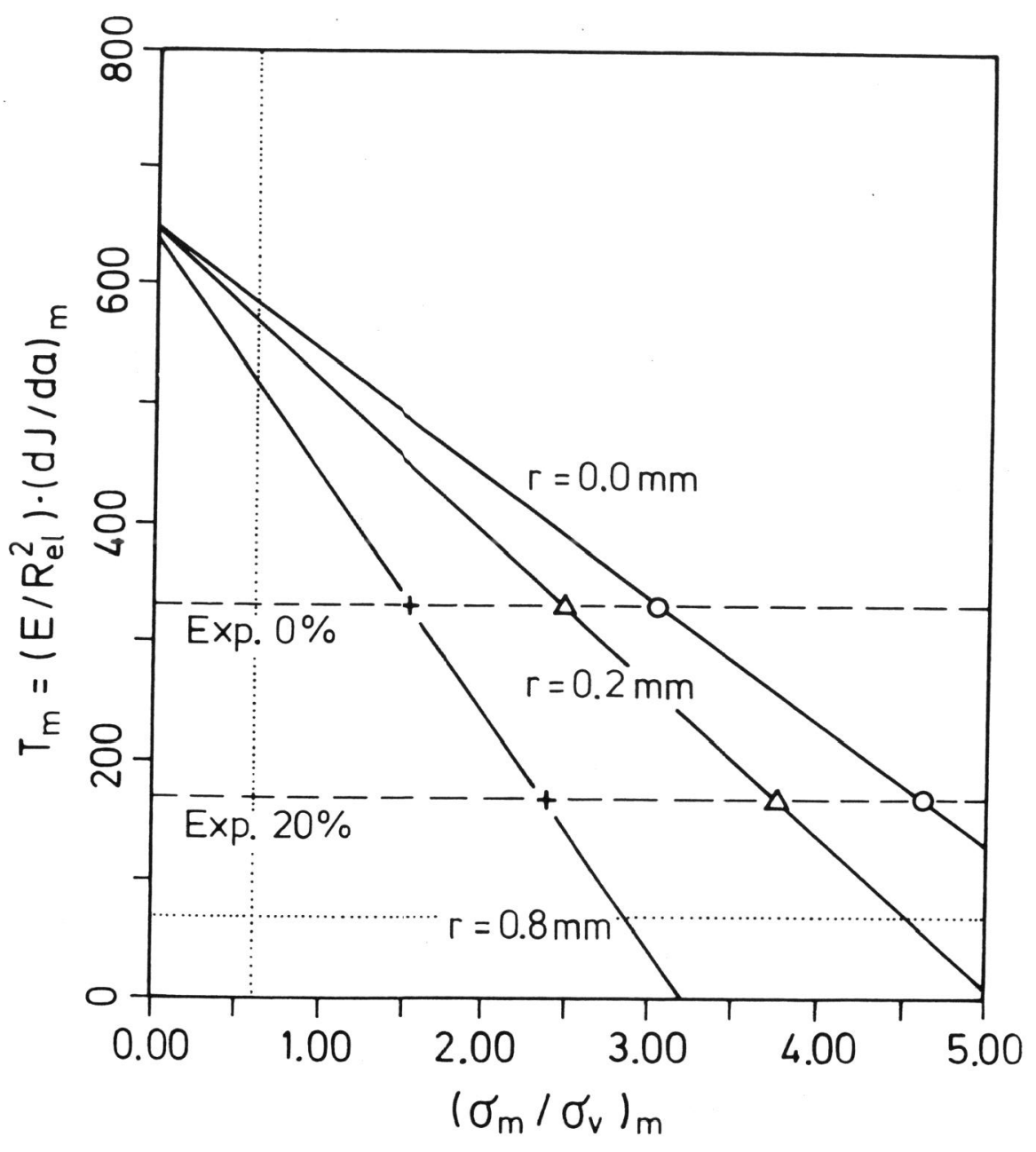

Fig. 12. Correlation of Slope $\Delta \mathrm{J} / \Delta \mathrm{a}$ with Mean Value $\left(\sigma_{\mathrm{m}} / \sigma_{\mathrm{v}}\right)_{\mathrm{m}}$ for Different Crack Tip Distances $r$.

Therefore, in Fig. 12 the experimentally from Fig. 7 determined $\Delta J / \Delta a$ - values for the two types of specimens $(0 \%$ sidegrooved: $\Delta \mathrm{J} / \Delta \mathrm{a} \approx 490 \mathrm{~N} / \mathrm{mm}^{2} ; 20 \%$ sidegrooved: $\Delta \mathrm{J} / \Delta \mathrm{a} \approx 250 \mathrm{~N} / \mathrm{mm}^{2}$ ) are plotted versus the corresponding $\left(\sigma_{\mathrm{m}} / \sigma_{\mathrm{v}}\right) \mathrm{m}_{\mathrm{m}}^{\text {-values calculated at }}$ different distances of the crack tip. As a first approximation a linear relationship is assumed and postulated by extrapolation for establishing the slope of resistance curves for cracks
As a first example the assessment of axial through-the-thickness cracks in a cylindrical vessel of $3 \mathrm{~m}$ length, $1.5 \mathrm{~m} \mathrm{dia-}$ meter and $40 \mathrm{~mm}$ wall-thickness based on $\mathrm{J}_{\mathrm{R}}$-curves will be considered (Aurich et al., 1986). In Fig. 13 the resulting $\mathrm{J}_{\mathrm{R}}$-curve is compared with those of different plane specimens. The plot demonstrates that the $J_{R}$-curves obtained for the double edge cracked tension (DECT) and the compact tension (CT) specimens describe a more severe constraint situation expressed by the lowest slope than the axial cracks ( $2 a=104$ to $450 \mathrm{~mm}$ ) in the vessel whereas the center cracked tension (CCT) specimens show the lowest constraint.

The situation described may be considered as a first step in the chain of transferability of results from specimens to components. In a next step the extension of surface cracks in components will be discussed. Investigations of this kind have been carried out for example in (Kordisch and the following Brocks et al.' results

Stable growth of a surface crack in a structure can be predicted when the local distribution of the loading parameter $J$ as the resistance $R$ are known. As an example fracture ex-

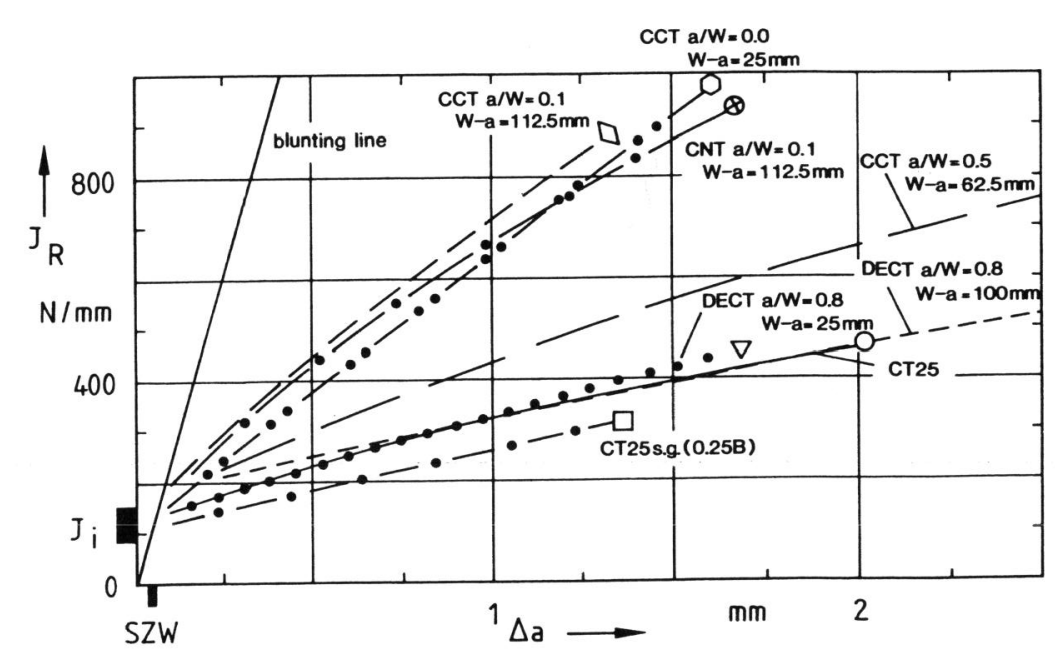

Fig. 13. $\mathrm{J}_{\mathrm{R}}$-Curves for Axial Through-the-Thickness Cracks in a Cylindrical vessel $(\varnothing=1.5 \mathrm{~m})$ and Three Different Types of Specimens; Steel ste 460 at $25 \pm 2{ }^{\circ} \mathrm{C}$. (Aurich et al. 1986) 


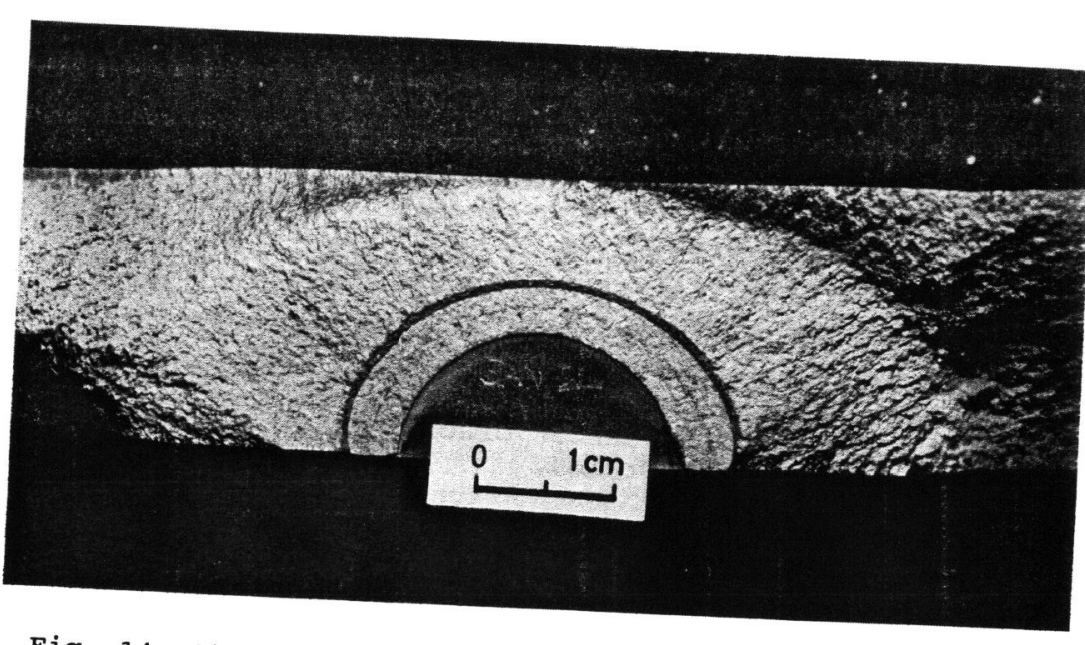

Fig. 14. Stable Growth of a surface Crack in a Plate of $\mathrm{X}$ CrMoV 12 1. (Klemm et al. 1988).

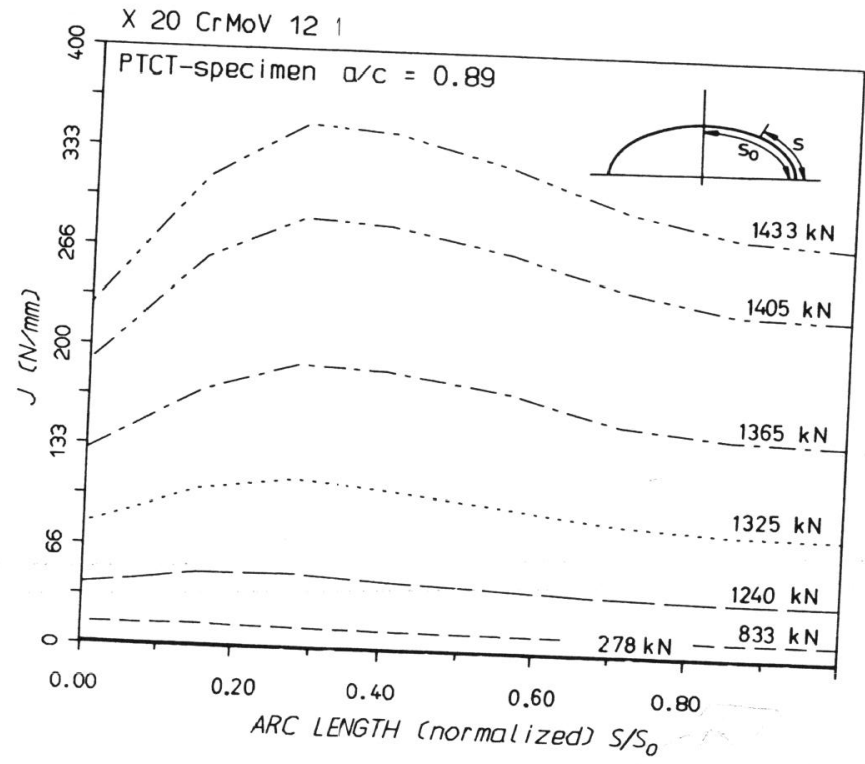
Fig. 15. J-Distribution at Several Load Steps Along the
Contour of a Surface Crack (a/c $=0.89$ al. 1988). periments are considered which are carried out in plates $(900 \mathrm{~mm} \times 120 \mathrm{~mm} \times 20 \mathrm{~mm}$ ) of the steel $\times 20 \mathrm{CrMoV} 121$ at room temperature. The original surface crack obtained by fatigue has een extended by stable crack growth when monotonic load was applied until the loading process was interrupted. The resulting stable crack growth surrounding the contour of the surface erack is shown as a dark zone on the fracture surface in rigk in order to predict the amount of stable growth in lig. 14. In order to predict the as guantitative The J-distributions at several load steps along the contour of this surface crack with the dimensions a/c $=$ the contour $t=0$ ion has been computed (Fig. 15) as well as the constraint distribution c $/ \sigma=h(r=0.3 \mathrm{~mm}, s)$ on the ligament along the crack ${ }_{\mathrm{m}} / \sigma_{\mathrm{v}}=\mathrm{h}(\mathrm{r}=0.3 \mathrm{~mm}, \mathrm{~s})$ on the ligament along the crack contour (Fig. 16). Since the local distribution of the resistance is unknown it can be constructed by determining the in dependence of the parameter $\mathrm{h}$ for this material. After constructing the local resistance curves and inserting the related local J-values according to Fig. 15 finally the local variation of the aluck extension a can be estimated. Although variation of the crack extension $\Delta a$ can bimplifying assumptions the resulting variation of the local crack extension $\Delta a(\mathrm{~s})$ is the resulting variation of the local crack extension a (s) (Fig. 17).

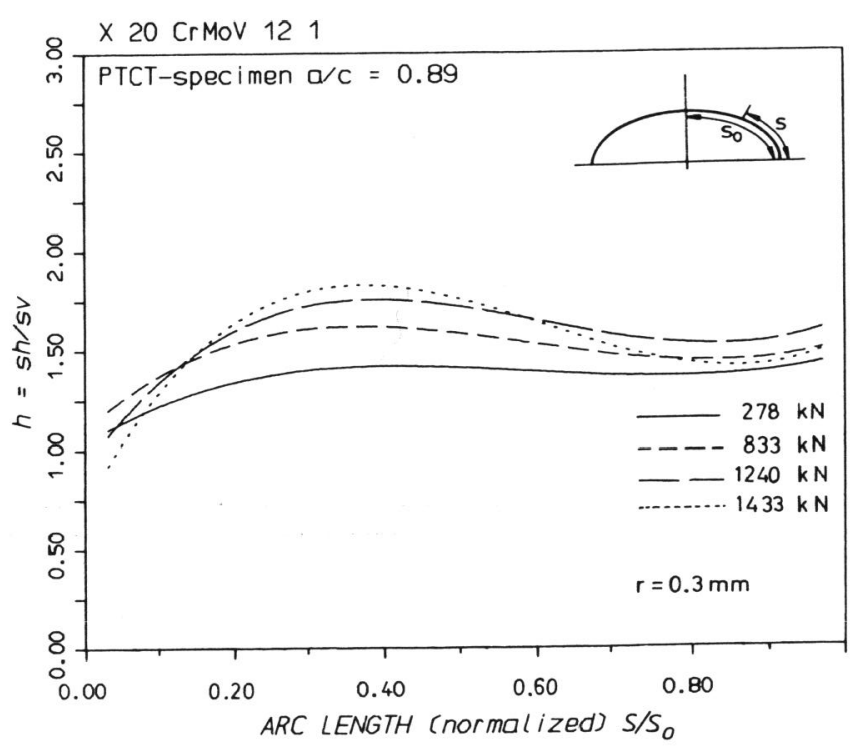

Fig. 16. $\sigma_{\mathrm{m}} / \sigma_{\mathrm{v}}=\mathrm{h}(\mathrm{s})$ at the Distance $\mathrm{r}=0.3 \mathrm{~mm}$ Along the Contour of the Same Surface Crack. (Klemm et al. 1988 . 


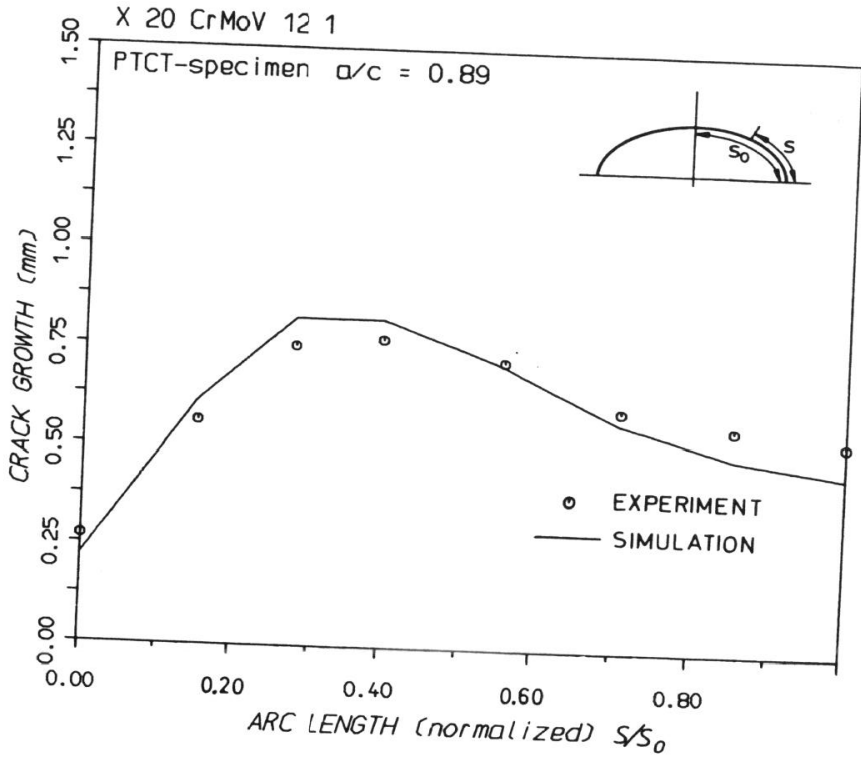

Fig. 17. Comparison of the Local Crack Extension the Same Surfa Experimentally Determined for the Same Surface Crack Configuration. (Klemm
et al. 1988.)

It is promising that results from other authors (Brocks et al. principal resultion in Aurich and Sommer) lead to the same the distribution $J(s)$ does not conditions where the maximum of shown for an outer surface crack (a/s = maximum of $\Delta a(s)$ as axial direction of a vessel ( $\sigma=1 \mathrm{a} / \mathrm{s}=.22, \mathrm{a} / \mathrm{t}=.51)$ in

3.

\section{CONCLUSIONS}

The basis for the assessment of the integrity of components and refuctures has been strengthened during the components and refined methods of EPFM. Furthermore the toust years by using servi obtained from small specimens to cmpons predice conditions has been extremely improved under actual prediction of growth characteristics of crov including the ing in ing in a stable manner that for the prediction crack extendcrack growth $\Delta a$ not only the variation of then of the local the variation of the crack contour has to be known, but also $\left(\sigma_{\mathrm{m}} / \sigma_{\mathrm{v}}\right)(\mathrm{s})$.

\section{REFERENCES}

Aurich, D. , K. Wobst, H. Krafka (1986). $\mathrm{J}_{\mathrm{R}}$-Curvces of Wide Plates and CT 25 Specimens; Comparison of the Results of a Pressure Vessel, 13. MPA-Seminar, stuttgart, 46.1 - 46.20. Aurich, D., E. Sommer (1988). The Effect of Constraint on Elastic-Plastic Fracture. Steel Research 8, 358-367.

ASTM Standards (19869), Philadelphia, Part 31.

ASTM E 813-82, Determination of $\mathrm{J}_{\mathrm{IC}^{\prime}}$ A Measure of Fracture Toughness. Annual Book of ASTM.

BAM-Forschungsbericht (1987). Analyse und Weiterentwicklung bruchmechanischer Versagenskonzepte auf der Grundlage von Forschungsergebnissen auf dem Gebiet der Komponentensicherheit, Teilvorhaben: Werkstoffmechanik, BAM, Berlin.

Bathe, K.H. (1980). Adina, a Finite Element Programm for Automatic Dynamic Incremental Nonlinear Analysis. Report 82 448-1, Massachussetts Institute of Technology, Cambridge, MA, USA.

Blauel, .G., L. Hodulak, T. Hollstein, B. Voss (1984). Material Characterization by $\mathrm{J}_{\mathrm{R}}$-Curves of a 20 MnMoNi 55 Forging. Int. J. Pres.Ves. \& Piping 17, 139-162.

Blauel, J.G., B. Voss (1986). Characterization of Ductile Material Behaviour by $\mathrm{J}_{\mathrm{R}}$-Curves. ECF 6 Fracture control of Engineering Structures, Vol. 1, Amsterdam.

Brocks, W. and H.-D. Noack (1987). Elastic-plastic FEM-Analysis of in Inner Surface Flaw in a Pressure Vessel. 9 SMiRT, Lausanne, /G4/3.

Brocks, W.' H. Krafka, W. Müller, K. Wobst (1988). Experimental and Numerical Investigations of stable Crack Growth of Axial Surface Flaws in a Pressure Vessel. Technischer Fachbericht, BAM, Berlin.

Brocks,W., G. Künecke, H.-D. Noack, H. Veith (1987). On the Transferability of Fracture Mechanics Parameters from to Structures Using FEM 13. MPA-Seminar, stuttgart.

Brocks, W. and H.-D. Noack (1987). Elastic-Plastic FEM Analysis of an Inner Surface Flaw in a Pressure Vessel. 9th Conference on Structural Mechanics in Reactor Technology, Lausanne, Vol. G, paper $4 / 3,1-7$.

Brocks, W., H. Krafka, W. Müller and K. Wobst. Experimental and Numerical Investigations of Stable Crack Growth of Axial Surface flaws in a Pressure Vessel. To be published in Proceedings of 6th Int. Conf. on Pressur Vessel Technology

Clausmeyer, H. (1969). Kritischer Spannungszustand und Trennbruch unter mechachsiger Beanspruchung. Konstruktion, 21, $252-59$

Hodulak, L., H. Kordisch, S. Kunzelmann and E. Sommer (1978). Influence of the Load Level on the Development of Part-Through cracks. Int. J. Fracture, 14, R35-R38. 
Hodulak, L., H. Kordisch, S. Kunzelmann and E. Sommer BWM-Bericht V1/77, Freiburg durchgehenden Rissen.

Fraunhofer-Institut

Fraunhofer-Institut für Werkstoffmechanik, Freiburg.

Numerical Investigation of Schmitt (1988). Experimental and Pipes. IAEA Specialists' Meeting on Cracks in Plates and Stuttgart.

Fracture Mechanics, San Antonio, 19th National Symposium on Fracture Mechanics, San Antonio, Texas, USA, 30.1-30.24.

Kordisch, H., E. Sommer and W. Schmitt (1987). The Influence of Triaxiality on Stable crack Growth. 13. MPA-Seminar,

(1979). J J.J. Menke, R.A. Gray, Jr. and J.R. Hawthorn Pressure Vessel steels. Washington of US NRC CSNI Special ists' Meeting University, Proceedings Instability, St. Louis, MO, Meeting on Plastic Tearing

Solutions of the "(1980). A Critical Evaluation of Numerical Solutions of the "Benchmark" Surface Flaw Problem, SESA.

Milne, I., R.A. Ainsworth, A.R. Dowling and A.T. Stewart taining Defects, R/H/R6 - Rev.

Newman, $T$ C. Jr. (1979)

Intensity Factors for A Review and Assessment of the StressLife Prediction, ASTM 687 (J) Cracks, Part-Through Crack

Roos, E. U. 16-42.

Ermittlung von Rißwid J-Integrals an GroBproben. 13. 6.1-6.25.

Roos, E., U. Eisele, H. Silcher and F. Spaeth (1986) der Werkstoffzähigkeit und des Spanungszustandes Einfluß das Versagensverhalten von Großproben. 12. MPA-Seminar.

Schmitt, W. (1986). Thre of Post Yield Fracturion Fracture Mechanics - Nonliniments. In: Computational

AMD-Vol. 61, 119-131.

Sommer, $E$.

Oberfle. (1984). Bruchmechanische Bewertung Oberflächenrissen, WFT Bd. 1, Springer/Berlin/Heidelberg/
New York/Tokyo.

Sommer, $\mathrm{E}, \mathrm{L}$.

Characteristics of Part-Through Kordisch (1977). Growth Plates and Pressure Vessel Technoctions of the ASME, J.

Problems and Computational The Surface crack: Physical 